\title{
Gestasyonel Diyabetik ve Nondiyabetik Gebelerin Glukoz, Lipid, Krom Seviyelerinin Sağlıklı Gruplara Göre Değişimlerinin İncelenmesi
}

\section{Investigation of Glucose, Lipid, Chromium Level Changes in Gestational Diabetic and Nondiabetic Pregnants Compared with Healthy Groups}

\author{
Adem Keskin $^{1 *}$, Emrullah Dorman ${ }^{2}$ \\ ${ }^{1}$ Aydın Kadın Doğum ve Çocuk Hastalıkları Hastanesi, Aydın, Türkiye \\ ${ }^{2}$ Atatürk Üniversitesi Tıp Fakültesi Biyokimya Ana Bilim Dalı, Erzurum, Türkiye \\ e-mail: ademkeskin78@gmail.com,emrullahdorman@gmail.com \\ ORCID: 0000-0003-1921-2583 \\ ORCID: 0000-0002-9713-7155 \\ *Sorumlu yazar/ Corresponding Author: Adem Keskin \\ Gönderim Tarihi / Received: 02.03.2020 \\ Kabul Tarihi / Accepted: 17.10.2020 \\ DOI: $10.34087 /$ cbusbed.697511
}

Giriş ve Amaç: Bu çalışmada, gestasyonel diyabet tanısı almış ve diyabetli olmayan gebeler ile aynı yaş grubunda gebe olmayan sağlıklı kadın bireylerin Açlık Kan Şekeri total kolesterol, trigliserit ve plazma krom parametreleri çalışılarak, bu metabolik parametrelerin, gebelik ile gestasyonel diyabetteki değişimleri ve birbirleri ile etkileşimlerinin incelenmesi amaçlanmıştır.

Gereç ve Yöntem: Bu çalışmaya, 50 adet gestasyonel diyabetli gebe, 50 adet diyabetli olmayan sağlıklı gebe ile 50 adet aynı yaş grubunda olan gebe olmayan sağlıklı kadın birey dahil edilmiștir. Hasta, gebe ve kontrol grubundan alınan kan örneklerinde açlık kan şekeri, total kolesterol, trigliserit ve plazma krom düzeyleri ölçülmüş̧ür.

Bulgular: Gestasyonel diyabetli grubun açlık kan şekeri ve plazma krom düzeyleri, diğer iki gruptan anlamlı yüksek çıkmıştır $(p<0.05)$. Gestasyonel diyabetli grubun total kolesterol ve trigliserit düzeyleri kontrol grubuna göre anlamlı yüksek çıkarken $(\mathrm{p}<0.05)$, nondiyabetik gebe gruptan anlamlı bir fark bulunmamıştır. Nondiyabetik gebe grubun trigliserit ve plazma krom düzeyleri, kontrol grubuna göre yüksek bulunmuştur $(p<0.05)$. Buna ek olarak tüm grupların plazma krom düzeyleri; vücut kitle indeksi, total kolesterol ve trigliserit düzeyleri ile pozitif korelasyon göstermektedir.

Sonuç: Bu çalışmada gestasyonel diyabetli hastalarda krom düzeyleri diğer iki gruba göre anlamlı olarak yüksek bulunmuştur. Plazma krom ile vücut kitle indeksi, trigliserit ve total kolesterol düzeyleri arasında pozitif korelasyon saptanmıştır. Krom ve diyabetin tüm türleri ile ilgili oldukça çelişkili yayınlar vardır, Gelecekteki araştırmaların dokuda krom düzeyini de kapsayacak biçimde, diyabetteki rolü üzerine olacağı öngörülmektedir.

Anahtar Kelimeler: Gestasyonel Diyabetes Mellitus, Glukoz, Krom, Total kolesterol, Trigliserit

\section{Abstract}

Objective: In this study, it is aimed to investigate the changes and interactions of these metabolic parameters in pregnancy and gestational diabetes and by studying fasting blood sugar, total cholesterol, triglyceride and plasma chromium parameters, in blood samples of pregnant women diagnosed with gestational diabetes, pregnant women without diabetes and healthy women who are not pregnant in the same age group

Materials and Methods: This study included 50 pregnant women with gestational diabetes, 50 healthy pregnant women without diabetes and 50 healthy non-pregnant women in the same age group. It was measured fasting blood sugar, total cholesterol, triglyceride and plasma chromium concentrations in blood samples taken from the patient and control groups 
Results: Fasting blood sugar and plasma chromium levels of gestational diabetes group were significantly higher than the other two groups ( $\mathrm{p}<0.05$ ). While the total cholesterol and triglyceride levels of the gestational diabetes group were significantly higher than the control group $(\mathrm{p}<0.05)$, there was no significant difference from the nondiabetic group. Triglyceride and plasma chromium levels of non-diabetic pregnant group were higher than the control group ( $\mathrm{p}<0.05$ ). Plasma chromium levels shows a positive correlation with Body mass index, total cholesterol and triglyceride levels of all groups.

Conclusion: In this study, chromium levels in gestational diabetes mellitus patients were found to be significantly higher than the other two groups. A positive correlation was found between plasma chromium and Body mass index, triglyceride and total cholesterol levels. There are quite contradictory publications on all types of diabetes and chromium. It seems to be on his role in diabetes, to include the level of chromium in the tissue of future research.

Key Words: Gestational Diabetes Mellitus, Glucose, Chrome, Total cholesterol, Triglycerides

\section{Giriş}

Gestasyonel Diyabetes Mellitus (GDM), ilk olarak gebelikte ortaya çıkan ve gebelik sırasında tanı konulan glukoz tolerans bozukluğudur [1]. GDM prevalansı, değişik ülke ve etnik gruplar için farklılık göstermekle beraber, \%1-14 arasında değişmektedir [2,3]. Diyabete bağlı maternal mortalite ve morbidite $\% 30$ ve prenatal mortalite $\% 90$ oranlarında iken, insülinin klinik kullanıma başlamasından sonra maternal mortalite nondiyabetik gebeler seviyesine düşmüş ve prenatal mortalite de $\% 5$ 'e varan oranlara kadar inmiştir [4,5].

Gebelikte, karbonhidrat metabolizmasında önemli değişiklikler meydana gelmektedir. Gebelik süresince, maternal metabolizmasında ki değişiklikler ve fetoplasental ihtiyaçlardan dolayı gebenin günlük kalori ihtiyacı artar. Gebeliğin ilk yarısında östrojen ve progesteron artışına bağlı olarak pankreasta beta-hücre hiperplazisi meydana gelmektedir [6]. Beta-hücre hiperplazisi ile oluşan GDM, gebelikte en sik görülen endokrinolojik bozukluktur [7]. GDM hikayesi olan kadınlarda, 5-10 yıl içinde \%20-50 oranında tip 2 Diyabetes Mellitus (DM) gelişme riski vardır [8]. Diğer taraftan GDM olan kadınların çocuklarının ilerideki yaşam sürecinde obezite ve DM açısından risk altında olduğu belirlenmiştir [9]. GDM hikayesi olan kadınlar ve çocuklarında uygun takip ve yaşam tarzında yapılan değişikliklerle Tip 2 DM gelişmesi geciktirilebilmekte ya da önlenebilmektedir [10].

Önemli bir eser element olmanın yanında hayati bir antioksidan olan krom (Cr), glukoz duyarlılığını artırarak ve yüksek lipit düzeylerini azaltarak glukoz ve lipit metabolizmasında önemli bir rol oynar. Krom eksikliği normal glukoz toleransı ve sağlıklı lipid profillerinin korunmasını etkiler [11]. Besin gereksinimleri, normal hamilelik sirasinda, sadece vücudun ihtiyacının artması ile değil, aynı zamanda atılım nedeniyle de artar. Davidson tarafindan yapılan araştırmalar, plazma krom konsantrasyonlarının hamilelikte normalden önemli ölçüde düşük olduğunu ve bunun maternal depoların tükenmesinin yanı sıra normal fizyolojiyi de temsil edebileceğini göstermiştir [12]. Hamilelik sırasında krom atılımını inceleyen bir araştırma, normal gebeliklerde sürekli olarak artan atılımın, insülin duyarlılığında anlamlı bir azalma ile ilişkili göründügünü göstermiştir.
Ardından, artan krom atılımının bir anneyi, gebelik veya doğum sonrası diyabet geliştirme riskini arttırma potansiyeline sahip olduğu tahmin edilmiştir [13]. Bununla birlikte, kromun gebelik diyabeti üzerindeki etkisi bir tartışma konusu olmaya devam etmektedir. Bu kısmen, krom seviyelerini ölçmek için hangi yöntemin en iyi olduğu konusunda fikir birliği olmaması nedeniyledir.

Bu çalışmada, GDM'li bireylerde, diyabet olmayan gebelerde ve diğer gruplar ile aynı yaş aralığında olan sağlıklı kadın bireylerde açlık kan şekeri (AKŞ), total kolesterol, trigliserit (TG) ve Plazma Cr düzeylerinin değişimleri karşılaştırılarak araştırılmıştır.

\section{Materyal ve Metot}

Bu çalışma, Atatürk Üniversitesi Araştırma Hastanesi Kadın Hastalıkları ve Doğum kliniğinde ve Biyokimya laboratuarında gerçekleştirilmiştir, Araştırma tek merkezli klinik araştırma niteliği taşımaktadır. Araştırmanın etik kurul kararı, Atatürk Üniversitesi Tıp Fakültesi İlaç Dışı Klinik Araştırmalar Etik Kurulundan alınmıştır.

Oluşturulan gruplar, Atatürk Üniversitesi Araştırma Hastanesi Kadın Hastalıkları ve Doğum kliniğine başvuran 24-28 haftalık gebelerden rutin GDM taraması yapılan hastalar arasından ve sağlıklı kadın bireylerden seçilmiştir. Bu araştırmanın yapıldığı her bireye uygulanan işlemler anlatıldıktan sonra kendilerinin onayları alınmıştır. İki aşamalı tanı yaklaşımı [14-16] ile, GDM tanısı konulan 50 adet hasta grup 1 olarak belirlenmiştir. Grup 1 ile aynı yaş aralığında olan 50 adet nondiyabetik sağlıklı gebe birey, Grup 2 olarak belirlenmiştir. Kontrol grubu (Grup 3) olarak, grup 1 ile aynı yaş aralığında 50 adet gebe olmayan sağliklı (Diyabeti veya herhangi bi metabolic hastalığ 1 olmayan) kadın bireyler çalışmaya dahil edilmiştir.

Gebe olan gruplardan sorgulanan bilgiler; boy, gebelik döneminde aldıkları kilo ve vücut ağırlığıdır. Vücut Kitle İndeksi (VKİ): Vücut ağırlığ1 $(\mathrm{Kg}) /$ boy $\left(\mathrm{m}^{2}\right)$ olarak hesaplanmıştır. Her gruptaki bireylerin; AKŞ, total kolesterol, trigliserid ve plazma Cr düzeylerine bakılmıştır.

Kan örnekleri, 10-12 saatlik açlıktan sonra alınmıştır. AKŞ, total kolesterol ve trigliserid için kan örnekleri antikoagülansız jelli tüplere; plazma $\mathrm{Cr}$ analizleri için örnekler Etilendiamin tetraasetik asit (EDTA)'lı 
tüplere alınmıştır. AKŞ, total kolesterol ve trigliserit aynı gün içinde analiz edildi. Plazma $\mathrm{Cr}$ için kan örnekleri santrifüj cihazında 3000 rpm'de santrifüj edilerek plazmaları alınmıştır. Plazmalar ependorf tüplerine alınarak $\quad-80^{\circ} \mathrm{C}$ 'de dondurucuda çalışma gününe kadar muhafaza edilmiştir.

AKŞ; Heksokinaz yöntemiyle [17], Total Kolesterol; Spektrofotometrik CHO-POD yöntemiyle [18], Trigliserid; prosedürü, bir dizi birleşik enzimatik reaksiyona dayanan yöntemle [19] Beckman Coulter AU5800 Otoanalizör cihazında çalışıldı.

Standart Cr Çözeltisi; Merck firması tarafından temin edilen stok standarttan $(998 \pm 5 \mathrm{mg} / \mathrm{L})$ bir $\mathrm{mL}$ alınıp $\% 0,2$ 'lik HNO3 ile $100 \mathrm{~mL}$ 'ye tamamlanarak ara stok standart, bu ara stok standarttan $0.1,0.50,2.50,10$ $\mathrm{mg} / \mathrm{L}$ konsantrasyonunda standartlar hazırland. Krom için hazırlanan standart çözeltiler Grafit Fırın Atomik Absorbsiyon Spektrofotometre (Perkin Elmer AAnalyst 800 ABD) cihazıyla ölçüldü ve kalibrasyon eğrisi oluşturuldu.

Plazma kromu ölçümü için; Atomik Absorbsiyon Spektrofotometre $\mathrm{Cr}$ hollow katot lambası kullanılarak $357.9 \mathrm{~nm}$ 'de $1500^{\circ} \mathrm{C}$ piroliz sıcaklığında, $2300^{\circ} \mathrm{C}$ atomlaştırma sıcaklığında her örnekten $20 \mu \mathrm{L}$ alınarak grafit fırın içerisine konuldu. Oluşturulan kalibrasyon eğrisine karşıllk okutularak absorbans düzeyleri alınd1.

Verilerin istatiği, SPSS for Windows 19.0 (IBM,

USA) kullanılarak yapılmıştır. Gebe grupların kan örneklerinin alındığı gün itibari ile gebelik süresince aldıkları kilo farkı karşılaştırması için bağımsız örneklem T testi kullanıldı. Gruplar arası parametre karşılaştırmaları için Duncan Post Hoc testi kullanıldı. Krom düzeyleri ile VKİ parametreleri arasında korelasyon analizi için Pearson korelasyon testi kullanılmıştır. Deskriptif Tablosunda düzeyler ortalama \pm standart sapma ile verilmiştir. İstatistiksel olarak $\mathrm{p}<0.05$ düzeyleri anlamlı olarak kabul edilmiştir.

\section{Bulgular}

Grup 1; GDM tanısı almış hasta, Grup 2; nondiyabetik gebe ve Grup 3; Kontrol grubunu oluşturmaktadır. Her iki grubun kilo artışı arasında istatistiksel fark bulunmamaktadir $(\mathrm{p}>0.05)$.

Tablo 1. 24-28 Haftalık gebelik süresi boyunca kilo artışı.

\begin{tabular}{lccccc}
\hline & Grup & N & Ortalama & Standart Sapma & Standart Hata \\
\hline Ağırlık artışı (Kg) & Grup 1 & 50 & 8.42 & 2.865 & 0.405 \\
& Grup 2 & 50 & 8.06 & 2.142 & 0.303 \\
\hline
\end{tabular}

*Grup 1: GDM tanısı almış gebe, Grup 2: Nondiyabetik gebe

Kan örneklerinin alındığı gün itibari ile gebelik süresince aldıkları kilo bakımından yapılan bağımsız örneklem T testine göre; GDM'li grup ile sağlıklı gebe grup arasında anlamlı bir fark bulunmamıştır.

Tablo 2. Parametrelerin Gruplar Arası Karşılaştırılması

\begin{tabular}{|c|c|c|c|c|c|c|c|c|c|}
\hline & Grup1 & Grup2 & $\mathrm{P}$ & Grup1 & Grup3 & $\mathrm{P}$ & Grup2 & Grup3 & $\mathrm{P}$ \\
\hline \multirow{2}{*}{$\begin{array}{c}\text { Yaş } \\
\pm \mathrm{SD} \\
\end{array}$} & 30.92 & 29.54 & $\mathrm{P}>0.05$ & 30.92 & 30.00 & $\mathrm{P}>0.05$ & 29.54 & 30.00 & $P>0.05$ \\
\hline & \pm 4.69 & \pm 5.08 & & \pm 4.69 & \pm 5.72 & & \pm 5.08 & \pm 5.72 & \\
\hline \multirow{3}{*}{$\begin{array}{c}\text { VKİ } \\
(\mathrm{Kg} / \mathrm{m} 2 \\
\pm \mathrm{SD})\end{array}$} & 26.08 & 26.02 & $P>0.05$ & 26.08 & 21.1 & $\mathrm{P}<0.05$ & 26.02 & 21.1 & $\mathrm{P}<0.05$ \\
\hline & \pm 3.26 & \pm 3.02 & & \pm 3.26 & \pm 2.84 & & \pm 3.02 & \pm 2.84 & \\
\hline & & & & & & & & & \\
\hline \multirow{3}{*}{$\begin{array}{c}\text { AKŞ } \\
(\mathrm{mg} / \mathrm{dL} \\
\pm \mathrm{SD})\end{array}$} & 78.98 & 73.12 & $\mathrm{P}<0.05$ & 78.98 & 69.58 & $\mathrm{P}<0.05$ & 73.12 & 69.58 & $P>0.05$ \\
\hline & \pm 22.15 & \pm 8.42 & & \pm 22.15 & \pm 5.79 & & \pm 8.42 & \pm 5.79 & \\
\hline & & & & & & & & & \\
\hline & & & & & & & & & \\
\hline \multirow{3}{*}{$\begin{array}{l}\text { Koles. } \\
\text { (mg/dL } \\
\pm \mathrm{SD})\end{array}$} & 252.36 & 243.14 & $P>0.05$ & 252.36 & 228.00 & $\mathrm{P}<0.05$ & 243.14 & 228.00 & $P>0.05$ \\
\hline & \pm 46.26 & \pm 47.39 & & \pm 46.26 & \pm 44.87 & & \pm 47.39 & \pm 44.87 & \\
\hline & & & & & & & & & \\
\hline \multirow{3}{*}{$\begin{array}{c}\text { TG } \\
(\mathrm{mg} / \mathrm{dL} \\
\pm \mathrm{SD})\end{array}$} & 228.18 & 210.94 & $\mathrm{P}>0.05$ & 228.18 & 150.92 & $\mathrm{P}<0.05$ & 210.94 & 150.92 & $\mathrm{P}<0.05$ \\
\hline & \pm 94.16 & \pm 84.26 & & \pm 94.16 & \pm 75.36 & & \pm 84.26 & \pm 75.36 & \\
\hline & & & & & & & & & \\
\hline \multirow{3}{*}{$\begin{array}{c}\mathrm{Cr} \\
(\mu \mathrm{g} / \mathrm{L} \\
\pm \mathrm{SD})\end{array}$} & 2.52 & 1.56 & $\mathrm{P}<0.05$ & 2.52 & 0.78 & $\mathrm{P}<0.05$ & 1.56 & 0.78 & $\mathrm{P}<0.05$ \\
\hline & \pm 1.14 & \pm 1.05 & & \pm 1.14 & \pm 0.67 & & \pm 1.05 & \pm 0.67 & \\
\hline & & & & & & & & & \\
\hline
\end{tabular}

*Grup 1: GDM tanısı almış gebe, Grup 2: Nondiyabetik gebe, Grup 3: Sağlıklı Kontrol VKİ: Vücut Kitle İndeksi, AKŞ: Açlık Kan Şekeri, Koles: Kolesterol, TG: Trigliserid, Cr: Krom 
AKŞ ölçüm sonuçlarında; grup 1'in düzeyleri, diğer iki gruba göre yüksek çıkmıştır $(\mathrm{P}<0.05)$. Total kolesterol ölçüm sonuçlarında; grup 1'in düzeyleri, grup 3'ün düzeyine göre yüksek çıkmıştır $(\mathrm{P}<0.05)$. TG ölçüm sonuçlarında; grup 3'ün düzeyleri, diğer iki gruba göre düşük çıkmıştır $(\mathrm{P}<0.05)$. Plazma $\mathrm{Cr}$ ölçüm sonuçlarında; grup 1'in düzeyleri, diğer iki gruba göre yüksek çıkmıştır. Bununla birlikte grup 2 'nin düzeyleri, grup 3'e göre yüksek çıkmıştır ( $\mathrm{P}<$ $0.05)$.

Tablo 3. Plazma Krom Düzeyi ile Diğer Parametreler Arasındaki Korelasyon

\begin{tabular}{llllll}
\hline & & VKİ & AKŞ & Kolesterol & Trigliserit \\
\hline Plazma Cr & $\mathrm{R}$ &, $328^{* *}$ &, 114 &, $214^{* *}$ &, $178^{*}$ \\
& P. (2-yönlü) &, 000 &, 165 &, 009 &, 030 \\
& $\mathrm{~N}$ & 150 & 150 & 150 & 150 \\
\hline
\end{tabular}

$* \mathrm{P}<0.05$ ** $\mathrm{P}<0.01$ VKİ: Vücut Kitle İndeksi, AKŞ: Açlık Kan Şekeri,Cr: Krom

Plazma Cr ile diğer parametreler arasında korelasyon analizi yapıldı. Bu analize göre, plazma $\mathrm{Cr}$ düzeyleri ile VKİ $(\mathrm{P}<0.01)$, kolesterol $(\mathrm{P}<0.01)$ ve trigilserit $(\mathrm{P}<0.05)$ düzeyleri arasında pozitif korelasyon göstermektedir.

\section{Tartışma}

Biyolojik aktif kromun izolasyonu ve karakterizasyonu alanında Davis ve Vincent tarafından yapılan bir çalışmada; Kromun insülin reseptörüne bağlanması sonucu, tirozin kinaz

aktivitesinin artmasını sağladığı sonucuna ulaşmışlardır [20]. Bu durum, hücre içi sinyal iletiminde tirozin kinaz'1 kullanan insülinin etkisinin artmasına yol açmaktadır [21]. Glukoz Tolerans Faktör (GTF) olarak adlandırılan biyolojik aktif krom ile; insülin etkisi artmakta ve böylece protein, yağ ve karbonhidrat metabolizmasını düzenlemede işlev gören temel bir diyet ajanı olduğunu ortaya koymaktadır. Kromun, insülin duyarlılığını artırarak ve glukoz intoleransını kaldırarak insülin sistemi üzerinde önemli yararlı etkiler sağlayarak, tip $2 \mathrm{DM}$, GDM ve glukoz toleransında önemli bir rol oynadığı gösterilmiştir [22].

DM'nin en sık görülen türü olan Tip 2 DM'li hastalarla yapılan birçok çalışmada; diyabetli hastaların krom düzeylerinin, sağlıklı bireylere göre düşük olduğu sonucuna ulaşılmıştır [23,24]. Bu çalışmaların ışığında,

Tip 2 DM'li hastalara tedavi amacıyla krom takviyesi verilmesi ile ilgili birçok çalışma yapılmıştır $[25,26]$. Tip 2 DM ve krom arasında ki ilişkiye yönelik yapılan bu çalışmalarda; krom düzeylerinin, Tip 2 DM'li hastalarda düşük olduğu ve krom takviyesinin de sınırlı bir etki ortaya koyduğu sonucuna ulaşılmıştır. Diğer bir taraftan ise; DM'nin gebelikte gözlenen türü olan GDM'de ise, krom düzeyleri ile ilgili çelişkili yayınlar vardır [27-32]. $\mathrm{Bu}$ bilgiler 1şı̆̆ğında; çalışmamızda 50 adet GDM'li birey, 50 adet sağlıklı gebe ve diğer gruplar ile aynı yaş aralığında 50 adet sağlıklı kadınlarda plazma krom, total kolesterol, TG, AKŞ düzeyleri ve VKİ bakılmıştır.

Çalışmamızda, GDM'li grubun Cr düzeyleri, diğer iki gruptan daha yüksek, nondiyabetik gebelerin $\mathrm{Cr}$ düzeyleri ise kontrol grubundan daha yüksek bulunmuştur. VKİ ile Cr düzeyleri arasında pozitif korelasyon saptanmıştır.

GDM'de Tip 2 DM olduğu gibi, pankreastan insülin salınımının artmasına karşılık, GDM'de, fetoplesental hormonların etkisi ile maternal insülin direnci artmakta ve birinci faz insülin etkisinin azalması hiperglisemiye yol açmaktadır. İkinci faz insülinin etkisi ile artmış insülin düzeyi, açlıkta maternal glukoz seviyesinde düşüşe yol açmaktadır. Bütün bu değişimler, fetüsün daha çok karbonhidrat kullanabilmesini sağlamaya yöneliktir. Gebelik haftası ilerledikçe hormonlara bağlı olarak, kolesterol, fosfolipid ve trigliseritlerin serum seviyelerinde fizyolojik bir artış izlenir. Bu durum, heterojen hiperglisemi yanıtına yol açan insülin direnci, obezite, insülin eksikliği veya anormal genetik faktörlere ek olarak diabetik gebede metabolik stresi daha da arttırır [33-34]. Çalışmamızda da bu bilgiler ile uyumlu şekilde GDM'li grubun AKŞ düzeyleri diğer iki gruba göre daha yüksek, Total kolesterol ve TG düzeyleri konrol grubuna göre daha yüksek gözlenmiştir.

Çalışmamızda elde edilen Cr ve VKİ sonuçları ile uyumlu şekilde; Houldsworth A, ve ark. (2017) yaptıkları çalışmada da GDM'li grubun serum $\mathrm{Cr} /$ VKİ düzeyleri, nondiyabetik olanlara göre yüksek çıkmıştır. Ayrıca insülin düzeylerine bakılan bu çalışmada, analizi yapılan serum $\mathrm{Cr} / \mathrm{VKI}$ düzeyleri, insülin düzeyleri ile oranlandığında gruplar arasındaki farkın ortadan kalktığı görülmüştür [27]. Buna ek olarak; Saç telinde krom bakılan başka bir çalışmada ise; GDM'li grubun krom sonuçları bizim çalışmamızı destekler biçimde yüksek bulunmuştur [28]. Benzer sonuca Ataanya ve arkadaşlarının (2018) serum krom düzeyleriyle yaptıkları çalışmada da rastlanılmaktadır [29]. Jovanovic ve arkadaşlarının (1999) yaptığı bir çalışmada ise, GDM'li kadınlara yönelik krom takviyesinin, glukoz intoleransını düzelttiği ve hiperinsülinemiyi azalttığı gösterilmiştir [30].

Diğer bir taraftan; Scott E. ve ark. (2008) yaptıkları bir çalışmada ise, GDM'li kadınlar ile diyabetik olmayan kadınlar arasında anlamlı bir farklılık gözlenmemiştir [31]. Ancak bu çalışmada GDM'li grup, diğer gruba göre daha yaşlı olduğu belirtilmektedir. Sundararaman ve ark. aynı yaş 
aralığında olan gruplarla yaptıkları bir çalışmada da; GDM'li kadınların, nondiyabetik gebe kadınlara göre daha düşük serum krom seviyelerine sahip olduğunu saptamışlardır [32]. Ancak bu çalışmada; Kromun vücuttaki dağılımının, krom sonuçlarına etkisini standardize etmek amaciyla gerekli olan VKI ölçümüne yönelik bir kıyaslama bulunmamaktadır.

Gebelikte krom seviyelerine bakılan bir çalışmada, gebeliğin 16. ve 38. haftalarda yapılan ölçümlerde, gebelik süresince krom seviyelerinin yükseldiği saptanmıştır. Ayrıca bu haftalarda yapılan oral glukoz yüklemesinin ardından krom düzeylerinde yükseldiği gözlenmiştir [35]. Çalışmamızda da sağlıklı gebe grubun krom düzeyleri, sağlıklı kontrol grubuna göre daha yüksek gözlenmiştir. Glukoz toleransı bozulmamış gebelerde çok sayıda parametrenin etkisi ile insülin duyarlılığında azalma gelişmekte ve bu azalma gebeliğin ilerlemesiyle artmakta, obez gebelerde bu azalış gebe kalmadan önce başlamaktadır. GDM'li bireylerde insülin duyarlılığındaki azalmanın özellikle gebeliğin son döneminde artarak \%40'lara ulaştığ1 rapor edilmektedir [36].

Literatürde yer alan çalışmalarla kromun insülinin etkisini artırıcı rol oynadığ 1 ve bu fonksiyonu; insülin reseptörüne bağlanarak, tirozin kinaz aktivitesi üzerinden gerçekleştirdiği belirtilmektedir Bununla birlikte Krom-insülin kompleksi verilen farelerde, Krom-insülin kompleksinin insülin klerensini azalttığ ${ }_{1}$ ve ubikitin-proteazom yolunu baskılayarak, insulin reseptor substrat (IRS)-1 ve IRS-2'nin yapısının bozulmasını önleyerek insülinin hücre içi sinyalinizasyonunu artırdığ 1 belirtilmektedir [38].

GDM ile krom arasındaki ilişkiye yönelik yapılan çalışmalarda çelişkili sonuçların bulunması, yaş, VKİ, çalışmaların yapıldığı bölgesel farklılıklar ve etnisite kriterlerinden kaynaklandığı düşünülmektedir. Gebelikte artan VKİ ile korele şekilde krom düzeyleri de yükselmektedir. GDM'li bireylerde saptadığımız yüksek krom düzeyleri; diğer iki gruba göre yükselen AKŞ düzeyleri karşısında azalan insülin duyarlılığınını önlemek amacıyla ortaya çıkmış olabilir.

\section{Sonuc}

Sonuç olarak bu çalışmada, GDM'li grubun $\mathrm{Cr}$ düzeyleri, diğer iki gruptan, nondiyabetik gebelerin $\mathrm{Cr}$ düzeyleri ise kontrol grubundan yüksek bulunmuştur. Buna ek olarak, $\mathrm{Cr}$ düzeyleri ile kolesterol, trigliserit ve VKİ düzeyleri (her üçü ile de) arasında pozitif korelasyon saptanmıştır. Çalışmamızda saptadığımız yüksek krom düzeyleri, insülin duyarlılığındaki azalmayı önlemek amacıyla ortaya çıkmış olabilir. Krom ve Diyabetin tüm türleri ile ilgili oldukça çelişkili yayınlar vardır. Gelecekteki araştırmaların dokuda krom düzeyini de kapsayacak biçimde, diyabetteki rolü üzerine olacağ 1 öngörülmektedir.

\section{Referanslar}

1. Turok, D.K, Ratcliffe, S.D, Baxley, E.G, Management of gestational diabetes mellitus, American Family Physician, 2003, 68, 1767-1772.

2.Harris, S.B, Caulfield, L.E, Sugamori, M.E, Whalen, E.A, Henning, B, The epidemiology of diabetes in pregnant native Canadians, a risk profile, Diabetes Care, 1997, 20, 1422-1427.

3. Mazze, R.S, Krogh, C.L, Gestational diabetes mellitus: Now is the time for detection and treatment, Mayo Clinic Proceedings, 1992, 67, 995-1002.

4.Langer, O, Yogev, Y, Most, O, Xenakis, E, M, Gestational diabetes: The consequences of not treating. American Journal of Obstetrics \& Gynecology, 2005,192, 989-997.

5. Fan, Z.T, Yang, H.X, Gao, X.L, Lintu, H, Sun, W.J, Pregnancy outcome in gestational diabetes, International Journal of Gynecology \& Obstetrics, 2006, 94, 12-18.

6. Moore, P, Kolterman, O, Weyant, J, Olefsky, J.M, Insulin binding in human pregnancy: comparisons to the postpartum, luteal, and follicular states. The Journal of Clinical Endocrinology \& Metabolism, 1981, 52, 937-941.

7. Menato, G, Bo, S, Signorile, A, Current management of gestational diabetes mellitus, Expert Review of Obstetrics \& Gynecology, 2008, 3, 73-91.

8. Takiishi, T, Gysemans, C, Bouillon, R, Mathieu, C, Vitamin D and diabetes. Endocrinology and Metabolism Clinics of North America, 2010, 39, 419-446.

9. Silverman, B.L, Rizzo, T, Cho, N, H, Metzger, B.E, Long-term effects of the intrauterine environment, The Northwestern University Diabetes in Pregnancy Center Diabetes Care, 1998, 21 Suppl 2, 142-151.

10. Knowler, W.C, Barrett, Connor, E.Fowler, S.E, Hamman, R.F, Lachin, J.M, Walker, E.A, Nathan, D.M, Diabetes prevention program research $\mathrm{g}$. reduction in the incidence of type 2 diabetes with lifestyle intervention or metformin, New England Journal of Medicine, 2002, 346, 393-403.

11. Lewicki, S, Zdanowski, R, Krzyzowska, M, Lewicka, A, Debski, B, Niemcewicz, M, et al, The role of chromium III in the organism and its possible use in diabetes and obesity treatment, Annals of Agrienv Medicine, 2014, 2, 331-335.

12. Davidson, I, Burt, R, Physiologic changes in plazma chromium of normal and pregnant women: Effect of a glucose load, American Journal of Obstetrics and Gynecology, 1973, 116, $601-608$.

13. Morris, B.W, Samaniego, S, Fraser, R, Macneil S, Increased chromium excretion in pregnancy is associated with insulin resistance, The Journal of Trace Elements in Experimental Medicine, 2000, 13, 389-396.

14. Cosson, E, Benchimol, M, Carbillon, L, Universal rather than selective screening for gestational diabetes mellitus may improve fetal outcomes, Diabetes \& Metabolism, 2006, 32, 140146.

15. Griffin, M.E, Coffey, M, Johnson, H, Universal risk factor-based screening for gestational diabetes mellitus: Detection rates, gestation at diagnosis and outcome, Diabetic Medicine, 2000, 17, 26-32.

16. Rey, E, Hudon, L, Michon, N, Fasting plazma glucose versus glucose challenge test: screening for gestational diabetes and cost effectiveness, Clinical Biochemistry, 2004, 37, 780-784.

17. Czok, R, Barthelmai, W, Enzymatische bestimmungen der glucose in blut, Wiener Klinische Wochenschrift, 1962, 40, 585589.

18. Norbert, W, Tietz clinical guide to laboratory tests second edition, Saunders Philadelphia USA, 1991

19. Je, S, American Association for Clinical Chemistry Meeting Abstract, 34. Clinical Chemistry and Laboratory Medicine, 1993, 39, 1127.

20. Davis, C, M, Vincent, J, B, Isolation and characterization of a biologically active chromium oligopeptide from bovine liver, Archives of Biochemistry and Biophysics, 1997, 339, 335-343

21. Doğan A.L, Güç D, Sinyal iletimi mekanizmaları ve kanser. Hacettepe Tip Dergisi, 2004, 35, 34-42

22. Swaroop, A, Bagchi, M, Preuss, H, G, Zafra-Stone, S, Ahmad, $\mathrm{T}$, Bagchi, D, Benefits of chromium (III) complexes in animal and human health, The Nutritional Biochemistry of Chromium (III), 2019, 2, 251-278. 
23. Kazi, T.G, Afridi, H.I, Kazi, N, Jamali, M. K, Arain, M.B, Jalbani, N, et al, Copper, chromium, manganese, rron, nickel, and zinc levels in biological samples of diabetes mellitus patients, Biological Trace Element Research, 2008, 122(1), 1-18.

24. Morris, B.W, Macneil, S, Hardisty, C.A, Heller, S, Burgin, C, Gray, T.A, Chromium homeostasis in patients with type II (n1ddm) diabetes Journal of Trace Elements in Medicine and Biology 1999, 13,1-2, 57-61.

25. Costello, R.B, Dwyer, J.T, Bailey, R.L, Chromium supplements for glycemic control in type 2 diabetes: limited evidence of effectiveness, Nutrition Review, 2016, 74(7), 455-468.

26. Gu, Y, Xu, X, Wang, Z, Xu, Y, Liu, X, Cao, L et al, Chromiumcontaining traditional chinese medicine, tianmai xiaoke tablet, for newly diagnosed type 2 diabetes mellitus: a meta-analysis and systematic review of randomized clinical trials, EvidenceBased Complementary and Alternative Medicine, 2018, Article ID 3708637,8 pages

27. Houldsworth, A, Williams, R, Fisher, A, Demaine, A.G, Millward, B.A, Proposed relationships between the degree of insulin resistance, serum chromium level/bmı and renal function during pregnancy and the pathogenesis of gestational diabetes mellitus, International Journal of Endocrinology and Metabolism 2017, 3(1)

28. Aharoni, A, Tesler, B, Paltieli, Y, Tal, J, Dori, Z, Sharf, M, Hair chromium content of women with gestational diabetes compared with nondiabetic pregnant women, American Journal of Clinical Nutrition, 1992, 55, 104-107.

29. Ataanya, D.A, Larbie, C, The association between micronutrients levels and gestational diabetes: a cross sectional study in ashanti region, International Journal of Biochemistry Research \& Review 2018, 24(2), 1-8.

30. Jovanovic, L, Gutierrez, M, Peterson, C.M, Chromium supplementation for women with gestational diabetes mellitus, The Journal Of Trace Elements In Experimental Medicine, 1999, $12,91-97$.

31. Woods, S.E, Ghodsi, V, Engel, A, Miller, J, James, S, Serum chromium and gestational diabetes, Journal of the American Board of Family Medicine, 2008, 21, 153-157.

32. Sundararaman, P.G, Sridhar, G.R, Sujatha, V, Anita, V, Serum chromium levels in gestational diabetes mellitus, Indian Journal of Endocrinology and Metabolism, 2012, 16, 70-73.

33. Wilson, J.D, Poster, D.W, Diabetes in Williams textbook of endocrinology, 8 Bask1, WB Saunders Company, 1992, 9931005.

34. Hollngsworth, A.K, Endocrine and metabolic homeostasis in diabetic pregnancy, Clinics İ Perinatology, 1983, 10(3), 593614.

35. Hambidge, K.M, Droegemueller, W, Changes in plazma and hair concentrations of zinc, copper, chromium and manganase during pregnancy Obsterics and Gynecology, 1974, 44(5) 666-673.

36. Lain, K, Y, Catalano, P, M, Metabolic changes in pregnancy, Clinical Obstetrics and Gynecology, 2007, 50, 938-948.

37. Cefalu, W.T, Hu, F.B, Role of chromium in human health and in diabetes, Diabetes Care, 2004, 27, 2741-2751.

38. Wang Z, Q, Yu Y, Zhang X, Komoroski J, Chromium-insulin reduces insulin clearance and enhances insulin signaling by suppressing hepatic insulin-degrading enzyme andproteasome proteinexpression in kay mice, Frontiers in Endocrinology, 2014, 5, 1-6.

http://edergi.cbu.edu.tr/ojs/index.php/cbusbed isimli yazarın CBU-SBED başlıklı eseri bu Creative Commons Alint1-Gayriticari4.0 Uluslararas1 Lisans1 ile lisanslanmıştır. 